\title{
Нелинейные траектории интенсивности люминесценции единичных квантовых систем
}

\author{
Е.Ф. Мартынович \\ Иркутский филиал Института лазерной физики СО РАН \\ E-mail:femto@bk.ru
}

DOI: 10.31868/RFL2020.37

В работу квантовых генераторов и усилителей оптического излучения, пассивных лазерных затворов, люминофоров, различных люминесцентных сенсоров, как правило, вовлечены большие ансамбли рабочих квантовых систем. Вместе с тем, в последнее время значительный интерес проявляется к устройствам и датчикам, в которых работают одиночные квантовые системы $[1,2]$. Изучение единичных центров (атомов, молекул, дефектов в кристаллических и других конденсированных средах) дает новую информацию о свойствах этих систем, в том числе, о тех свойствах, которые имеют определяющее значение для практических приложений.

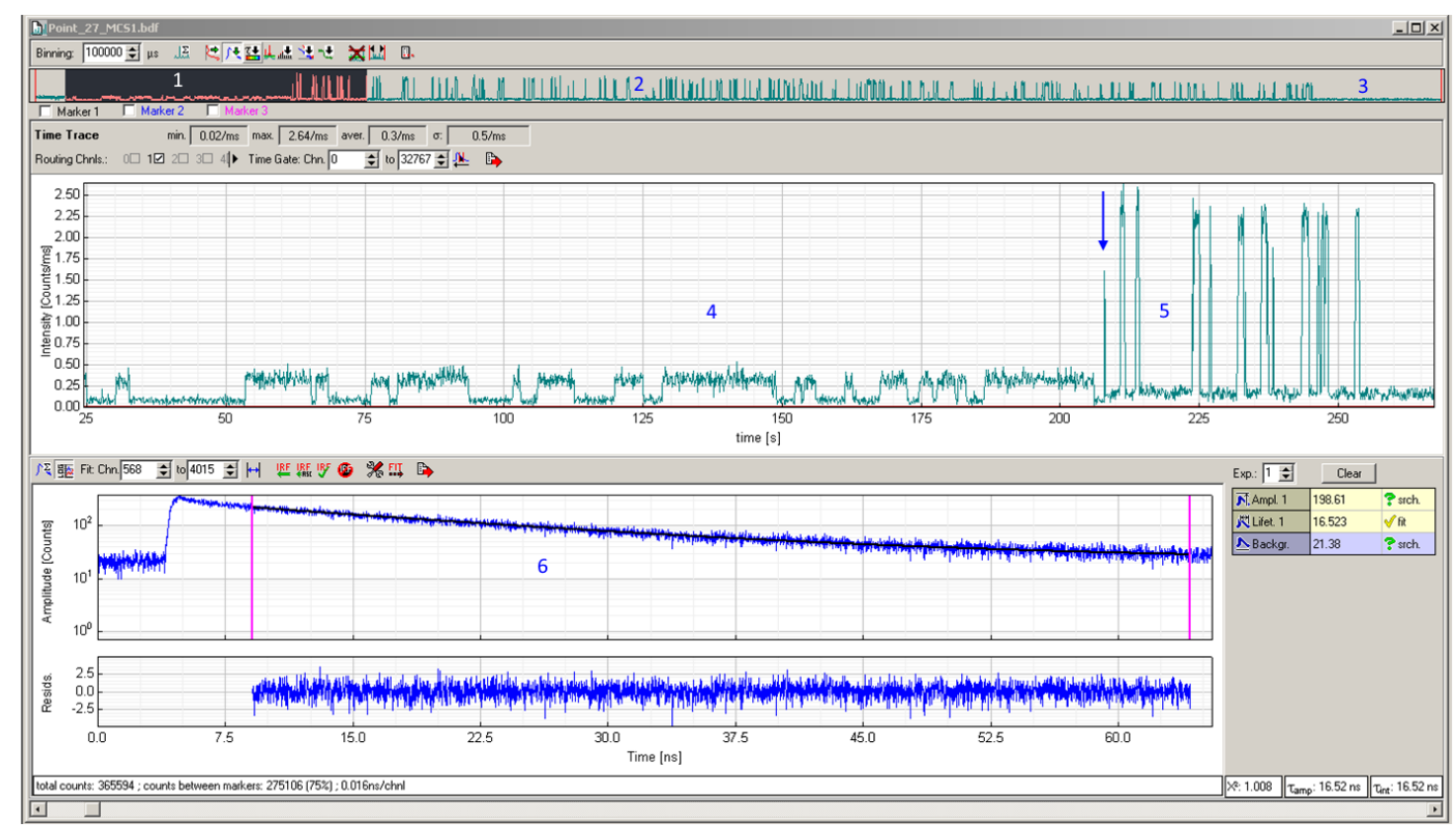

Рис. 1. Пример траектории интенсивности люминесценции единичного центра окраски в кристалле (1 - её фрагмент, выделенный черным цветом, показан ниже в увеличенном масштабе (4 и 5), 2 и 3 - продолжение траектории, 3 - фрагмент траекторий после фотохимического разрушения центра); 4 - часть траектории, записанная при низкой интенсивности возбуждения, 5 - её часть при высокой интенсивности, стрелкой показан момент переключения интенсивностей). 6 - кинетика нарастания и затухания интенсивности люминесценции исследуемого единичного центра.

В работе исследовались параметры траекторий интенсивности люминесценции одиночных центров, изучалась зависимость параметров от интенсивности возбуждения и по характеру этих зависимостей определялся механизм мерцаний.

\section{Литература}

[1] W.E. Moerner. Nobel Lecture (2014) https://www.nobelprize.org/uploads/2018/06/moernerlecture.pdf

[2] F. Kaneda, P. G. Kwiat. Science Advances, 5 (10): eaaw8586 (2019) DOI: 10.1126/sciadv.aaw8586 